\title{
Fault Zone Drilling in Subduction Zones: The Accomplishments of Ocean Drilling and Associated Studies
}

Subduction zones produce the world's largest earthquakes and cumulatively account for $90 \%$ of the global seismic moment release. The production of such large earthquakes is probably due to the shallow inclination (typically $<20^{\circ}$ ) of the major plate-boundary subduction thrust. Thus, in comparison to vertically-oriented transform faults, subduction thrusts have a large area in the seismogenic zone, or the depth interval mechanically capable of producing earthquakes.

Beginning with the later stages of the Deep Sea Drilling Program (DSDP) and continuing through the Ocean Drilling Program (ODP), Earth scientists have concentrated on drilling through the subduction thrust. Restrictions of the riserless drilling process required that the drilling focus on relatively shallow portions of the subduction thrust with burial depths limited to about $1 \mathrm{~km}$ below the seafloor.

Subduction thrusts convey the oceanic crust and overlying sedimentary deposits to the seismogenic zone and beyond. Hence, we can know the material that is entering the subduction thrust and trace its evolution with depth, both by direct sampling and experimental studies of its changing mechanical properties and mineral phases. Where drilled, subduction thrusts consist of zones of scaly mudstone 20-40 m thick. They are characterized by consolidative deformation where intergranular porosity is declining; these fault rocks include a fracture porosity and permeability that may be intermittently dilated by high fluid pressure. Hydrologic tests show that permeability varies with fluid pressure. Geochemical evidence suggests that separate fluid systems may exist around the subduction thrust, in the underthrust sediments, and in the subjacent oceanic crust. Geochemical evidence further suggests fluids associated with the subduction thrusts are typically far-traveled along this shallowly inclined fault.

Logging while drilling (LWD) has been an effective tool for determining in situ physical properties, establishing borehole structure, and inferring stress orientations in ODP boreholes in subduction zones. Physical property results indicate impedance values (velocity $\times$ density) that are consistent with the seismic reflection images. Structural features from analysis of LWD resistivity images are similar in orientation and type to those measured from reoriented cores. Borehole breakouts indicate stress orientations mirroring those determined from structural features of the borehole and also consistent with plate convergence vectors.

Because subduction thrusts dip shallowly, they may be well imaged with seismic reflection techniques. Seismic reflection images, coupled with drilling results, indicate that the fluids being expelled from the consolidating, dehydrating subduction zone deposits may be channelized during transport along the subduction thrust. Seismic data also suggest progressive underplating of the underthrust sediments with depth; the quantity of water in the underthrust sediments also diminishes with depth. Models, also well linked to drilling results, suggest the fluid pressure initially rises tens of kilometers landward of the deformation front and then diminishes towards the upper aseismicseismic transition along the subduction thrust.

A combination of seismological information and thermal models suggests that the upper aseismic to seismic transition begins at temperatures of about $125^{\circ} \mathrm{C}$. Here, the combined effects of consolidation and a series of diageneticmetamorphic reactions apparently foster the onset of stickslip behavior. At some localities incoming sediment may have been underplated by the depth of the seismogenic zone, leaving the basaltic oceanic crust as the lower plate of the subduction thrust. The fluid system of the oceanic crust, documented by ocean drilling, may be important here in controlling the mechanics of faulting.

Subduction thrusts probably transition from thick consolidating zones at shallow depths to more localized fault surfaces in the seismogenic zone. Candidates for such seismogenic faults in exhumed subduction complexes include layers of frictional melts (pseudotachylytes), zones of fluidized but unmelted fault rock, and intervals of conspicuous veining. A major challenge in drilling into the seismogenic zone will be recognition of the active fault surface, especially when it is included in a large volume of previously deformed rocks. Careful inspection of borehole images and cores, as well as monitoring of the borehole, will be essential in unequivocal specification of the active subduction thrust at depth.

\section{Author}

J. Casey Moore, Earth and Planetary Sciences, University of California Santa Cruz, Santa Cruz, Calif., 95064, U.S.A., e-mail: cmoore@es.ucsc.edu. 